\title{
GRYNFELT HERNIA
}

\author{
Hérnia de grynfelt \\ Camila ALCOFORADO, Natália URA, Flávio KREIMER,Euclides Dias MARTINS-FILHO, Álvaro Antônio Bandeira FERRAZ
}

From the Department of General Surgery, Hospital das Clínicas, Federal University of Pernambuco, Recife, PE, Brazil

\author{
Correspondence: \\ Álvaro Antônio Bandeira FERRAZ \\ E-mail: aabf@truenet.com.br \\ Financial source: none \\ Conflicts of interest: none \\ Received for publication: 30/03/2012 \\ Accepted for publication: 23/01/2013
}

\section{INTRODUCTION}

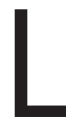

umbar hernia is defined as the presence of failure in the transversalis fascia and aponeurosis of the transversus abdominis muscle which results in the extrusion of the intra/ or extra-peritoneal discontinuity through the posterolateral abdominal wall. It is an unusual defect, corresponding to 1.5 to $2 \%$ of all abdominal wall hernias, with few cases described in the literature médica ${ }^{3,8,13}$. The lumbar hernias are divided into upper (Grynfeltt) and lower (Petit). Its diagnosis is based on high index of suspicion and confirmed by clinical examination and imaging methods of the abdomen, such as ultrasound, computed tomography or magnetic resonance. Like other types of hernias can develop complications. There are reports of incarceration, strangulation, ischemia and bowel perforation, and also reports of urgent surgical treatment. It consists of surgery of the abdominal wall synthesis in a posterolateral region; synthetic materials may be used, as meshes, to reinforce the suture, due to simple repair is difficult based on presence of fixed bone margins. This leads repair into tension, which have a high recurrence rate. However, these recurrences have not been described in the literature sufficiently to the present day. In rare cases of lumbar hernias incarcerated, it is necessary to perform bowel resection. Grynfeltt hernia is uncommon, and even more rare in bilateral presentation. To date, are described in the English medical literature about 300 cases of lumbar hernias ${ }^{3,8.13}$. This disease is unknown by most doctors whose diagnosis is simple and often not done or done in a wrong way.

\section{CASE REPORT}

Three men aged between 52 and 75 years were admitted to the clinic of General Surgery, Hospital de Clínicas, Federal University of Pernambuco, Recife, PE, Brazil in 2010, complained of pain and a tumor in the lumbar region. The three denied history of trauma, previous operations in this location or factors that would increase intra-abdominal pressure such as chronic cough, constipation or symptoms of prostatism. Physical examination showed reducible tumors increasing with efforts (Figure 1). In all three cases were observed hernias resulting from the failure of the superior lumbar triangle (Grynfeltt hernia), bilateral in two patients.

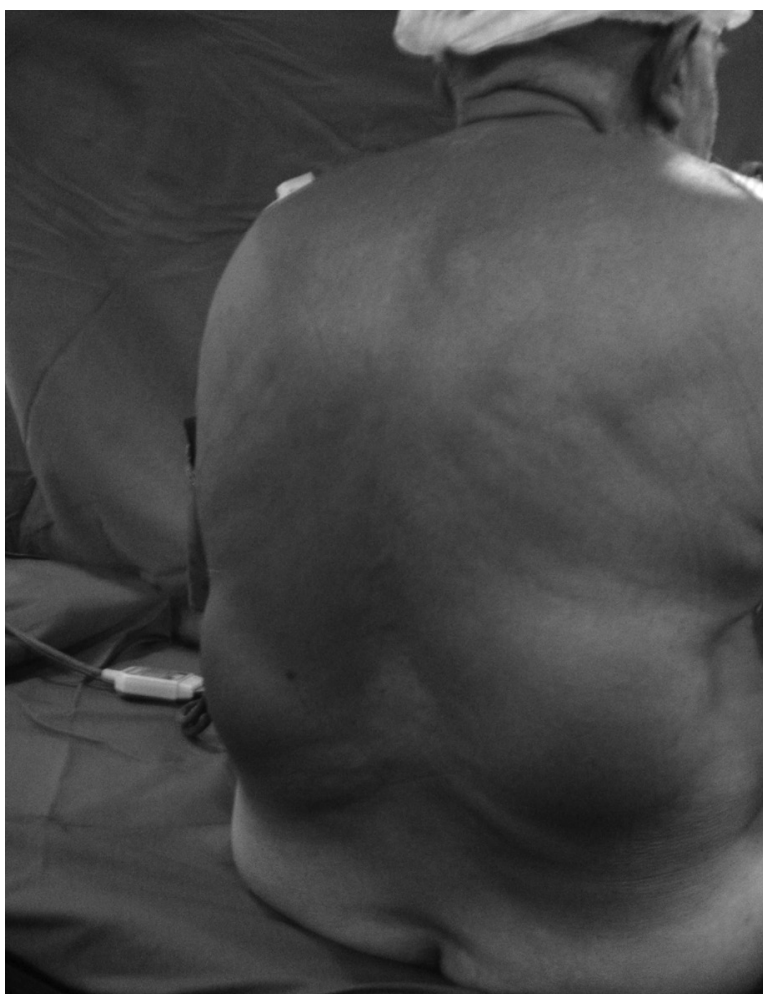

FIGURE 1 - Right lumbar hernia with visible tumor in this region

After the clinical diagnosis of lumbar hernia, patients underwent surgical correction. At the operation they were placed in lateral decubitus and transverse 
incision in the apex of the hernia was done. There wasn't hernial sac but only weakness of the aponeurosis of the transversus abdominis, through witch preperitoneal fat was coming from (Figure 2). Prolene ${ }^{\circledR}$ mesh was fixed over the aponeurosis with final closed drainage system in subcutaneous area (Figure 3).

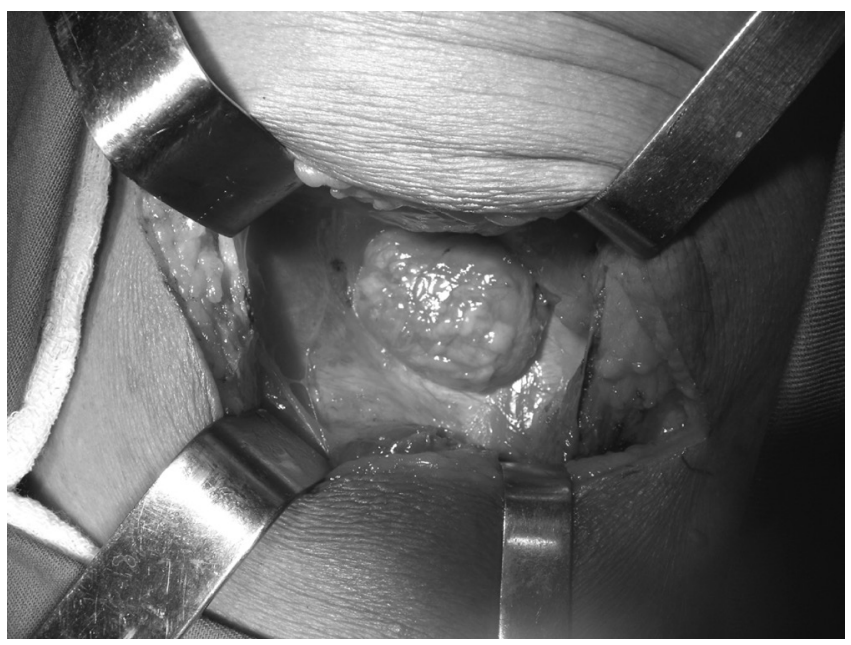

FIGURE 2 - Weakness of the aponeurosis of the transversus abdominis with preperitoneal fat on it

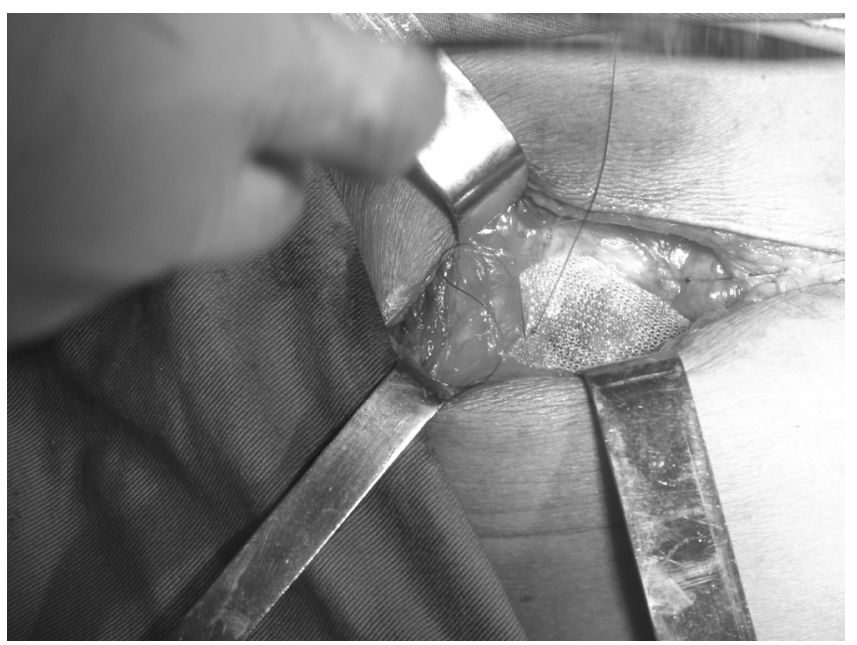

FIGURE 3 - Prolene ${ }^{\circledR}$ mesh being fixed over aponeurosis on hernia site

The three patients had no complications during the postoperative period and discharged after drain removal. Patients remain in outpatient follow-up with remission of symptoms and no recurrence of hernia or other significant postoperative complications, such as infections or chronic pain.

\section{DISCUSSION}

The lumbar hernias are known since the year 1672 , when Barbette, has suggested its existence ${ }^{8}$. However, the confirmation came only in 1731 , when DeGarangeot described the reduction of a lumbar hernia during autopsies $^{3}$. In 1750 Ravaton did the correction of a strangulated lumbar hernia in a pregnant ${ }^{8}$. In the English literature, are described about 300 cases $^{1,6-10,3,8,13}$. The superior lumbar triangle is bounded by the lower border of the $12^{\text {th }}$ rib, para-spinal muscles and the internal oblique muscle, whose roof is formed by the latissimus dorsi and the floor by the transversus abdominis. The lower lumbar triangle is drawn by the latissimus dorsi muscle, external oblique and iliac crest, whose floor is formed by the transversal fascia, aponeurosis of the internal oblique muscle, lombodorsal fascia and the roof by the superficial lombodorsal fascia ${ }^{1,3,7,8,1013}$. The existence of anatomical weakness in these areas favors the emergence of lumbar hernias, due to points of departure of the posterior branches of the lumbar nerves and vascular structures, as well as openings in the fascia secondary to trauma or bad embryological development. There are also diffuse lumbar hernias, in which the exact area of the defect is not well defined and the hernia extends throughout the lumbar region ${ }^{8}$.

More frequently lumbar hernia is unilateral, twice frequent on the left and in patients between the $5^{\text {th }}$ and $7^{\text {th }}$ decades of life ${ }^{1,6,7}$. About two thirds are found in male $1,6,10,13$. The most common location is the top of lumbar triangle, probably reflecting the fragility of this area, where the botton is just the transversal fascia. Bilateral lumbar hernias are rare and it is believed that defects are congenital ${ }^{1}$.

Primary hernias are more common in the elderly, in severe weight loss and situations that increases in intraabdominal pressure, representing $50 \%$ of all cases. The cause are weakness of the posterior abdominal wall ${ }^{1}$, secondary result of previous operations, infections , trauma or retroperitoneal hematomas (30\%). The remaining $20 \%$ correspond to those of congenital origin, which are most commonly found in children ${ }^{10.6-8,10-13}$. Usually when there is a bag, the presence of welldefined, mostly with colon inside, but other abdominal organs can pass back through the defect $6,7,10$.

Clinically, lumbar hernias present as bulges in the posterior region of the abdomen protruding with increased intra-abdominal pressure and disappear with the prone position. Most patients complain of discomfort or pain with different degrees of intensity in the lumbar region; others have no symptons s $^{3,6-8,10,13}$. May also have nausea, vomiting and abdominal cramps, which leads to clinical suspicion of strangulation hernia. On physical examination, the area of weakness can be detected by palpation, which can be painful. Furthermore, there is an increased back volume on the Valsalva maneuver and also with other conditions that raise intra-abdominal pressure ${ }^{1,6-8}$. Sometimes it can also have bowel sounds on auscultation and percussion ${ }^{7,8}$. If the diagnosis remains uncertain, imaging can confirm the diagnosis. Through them can also be obtained additional information about the anatomy, its degree of local distortion and nature of the contents of the 
sac. The diagnosis of this type of hernia is simple, being almost always based on clinical history and physical examination. Often misdiagnosis is performed, being a major lipoma the cause. Tomography should be used for the routine investigation, since it outlines the muscle layers of the right posterior abdominal wall and shows the defect, regardless of the presence or absence of hernia sac content ${ }^{3}$.

Complications of lumbar hernias are similar to other types of others: incarceration in $25 \%$ of case, with or without signs of intestinal obstruction, and strangulation in up to $18 \%^{1,6,8-10,13}$.

The only treatment available is surgery and it should be performed as early as possible, correcting the primary defect $t^{1,3,8,10}$. The goal is to reconstruct an abdominal wall elastic and firm, able to withstand the stress of daily physical activity ${ }^{7}$. Can be made oblique or transverse incisions according to the preference of each surgeon ${ }^{18}$. When found, the sac should be dissected, opened, explored and had its excess resected. If not possible, due to the presence of a large base, the sac should be everted and plicated with simple suture ${ }^{8}$.

The repair of Grynfeltt hernias can use conventional surgery or laparoscopy. Is recommended suture in double layer. In the first, the transversal fascia must be repaired and the second, the fascia of the internal oblique muscle is approximated to the fascia of the serratus posterior. Currently, the use of meshes is universally accepted, particularly when the defect is big $^{8}$. It is rarely necessary to perform enterectomies ${ }^{13}$. Seroma formation is common as postoperative complication, present in $35 \%$ of patients ${ }^{8}$. In general have a good evolution.

\section{REFERENCES}

1. Armstrong O, Hamel A, Grignon B, NDoye JM, Hamel O, Robert R, Rogez JM. Lumbar hernia: anatomical basis and clinical aspects. Surg Radiol Anat. 2008 Oct;30(7):533-7.

2. Barbette P. Opera chirurgico-anatomica. Lugduni, Gelder, 26. 1672.

3. Cesar D, Valadão M, Murrahe RJ. Grynfelt hernia: case report and literature review. Hernia. 2012 Feb;16(1):107-11.

4. Moreno-Egea A, Baena EG, Calle MC, Martínez JA, Albasini JL. Controversies in the current management of lumbar hernias. Arch Surg. 2007 Jan;142(1):82-8.

5. Ravaton $\mathrm{H}$. Traite dês plaies d'ares a feu. 277. 1750

6. Renck DV, Gomes LM, Júnior JIL. Hérnia lombar adquirida secundária do tipo Grynfelt: relato de caso. Radiol Bras. 2009;42(2):137-138.

7. Sharma LT, Col P. Lumbar Hernia. MJAFI 2009; 65: 178-179. Disponível em: http://medind.nic.in/maa/t09/i2/maat09i2p178. pdf. Acesso em: 14 de fevereiro de 2010.

8. Skrekas G, Stafyla VK, Papalois VE. A Grynfeltt hernia: report of a case. Hernia. 2005 May;9(2):188-91.

9. Tavares-de la Paz LA, Martínez-Ordaz JL. Lumbar hernia. Case report and literature review. Cir Cir. 2007 Sep-Oct;75(5):381-4.

10. Teo KA, Burns E, Garcea G, Abela JE, McKay CJ. Incarcerated small bowel within a spontaneous lumbar hernia. Hernia. 2010 Oct;14(5):539-41.

11. Tung HKS, Cheung SCW, Lee R, Chan FL. Bilateral Spontaneous Lumbar Hernia: Computed Tomografic Diagnosis. Department of Radiology, Queen Mary Hospital, Hong Kong. 2002

12. Wakhlu A, Wakhlu AK. Congenital lumbar hernia. Pediatr Surg Int. 2000;16(1-2):146-8.

13.Zhou X, Nve JO, Chen G. Lumbar hernia: clinical analysis of 11 cases. Hernia. 2004 Aug;8(3):260-3. 